\title{
Graves' Disease in Senegal: Clinical and Evolutionary Aspects
}

\author{
A. Sarr*, D. Diédhiou, N. M. Ndour-Mbaye, D. Sow, I. M. Diallo, S. El Alaoui, M. Diouf, \\ S. N. Diop \\ Department of Internal Medicine II, Abass Ndao Hospital Centre, Cheikh Anta Diop University, Dakar, Senegal \\ Email: ‘annasarr@orange.sn, dembadiedhiou1976@gmail.com, mbayester@gmail.com, \\ drdjiby@yahoo.fr, ibrahimamanediallo@hotmail.fr, saidnorou@yahoo.fr
}

Received 5 July 2016; accepted 8 August 2016; published 11 August 2016

Copyright @ 2016 by authors and Scientific Research Publishing Inc. This work is licensed under the Creative Commons Attribution International License (CC BY). http://creativecommons.org/licenses/by/4.0/

c) (i) Open Access

\section{Abstract}

Objectives: To assess the clinical particularities and management of Graves' disease at the Medical Clinic II of the Abass Ndao Hospital Centre in Dakar. Patients and methods: This was a retrospective, descriptive study on records of patients monitored for Graves' disease from 1 January 2010 to 31 December 2014 (5 years). Socio-demographic, clinical treatment and changing parameters were evaluated. Outcomes: 878 patients were included and among them 542 had been monitored for at least 18 months. The sex ratio (M/F) was 0.2 and the average age was $34.8 \pm 12$ years. The average consultation period was $10.7 \pm 2$ months. Free $\mathrm{T} 4$ at diagnosis was $>80 \mathrm{pmol} / \mathrm{l}(36.6 \%)$. Prolonged medical treatment was reported in $96.7 \%$ of patients. The average dose for initial therapy with Carbimazole was $37 \pm 9 \mathrm{mg} / \mathrm{day}$. Beta-blockers were used in $64 \%$ and anxiolytics in $40.5 \%$ of cases. The average period for administering the maintenance dose was 5.6 months. Patients' attendance and compliance stood at $17.7 \%$ and $53.1 \%$ respectively. Complications, mainly cardiothyreosis, were found in $13 \%$ of cases. Goitre regression was found in $13.9 \%$ of cases and that of exophthalmos stood at $19.5 \%$. Among our patients, $38.2 \%$ were lost to follow-up. The remission rate was $36.5 \%$ and thyroidectomy involved $14.5 \%$ of patients. Only stage of goiter ( $p=$ $0.007)$ and initial free $T 4$ value $(p=0.003)$ were statistically associated with remission. Conclusion: Graves' disease management raises follow-up problems. Indeed, the medical treatment is long while the number of patients lost to follow-up is high. As the only radical alternative available is surgery, it is therefore essential to promote the development of radioactive iodine therapy to expand the therapeutic choice.

\section{Keywords}

Graves' Disease, Treatment, Remission, Senegal

\footnotetext{
${ }^{*}$ Corresponding author.
}

How to cite this paper: Sarr, A., Diédhiou, D., Ndour-Mbaye, N.M., Sow, D., Diallo, I.M., El Alaoui, S., Diouf, M. and Diop, S.N. (2016) Graves' Disease in Senegal: Clinical and Evolutionary Aspects. Open Journal of Internal Medicine, 6, 77-82. 


\section{Introduction}

Graves' disease is an autoimmune hyperthyroidism characterized by a thyrotoxicosis syndrome, vascular diffuse goitre, exophthalmos and presence of anti-TSH receptor antibodies. It is the most common cause of hyperthyroidism with frequencies ranging from $45 \%$ to $60 \%$ [1] [2]. It usually occurs in young women $91.3 \%$ [1]. The choice of treatment differs depending on schools and continent. It is based on three methods of treatment: conservative medical treatment by synthetic anti thyroid drugs, thyroidectomy and radioactive iodine therapy [3]. In United States, radioactive iodine therapy is mostly used [4]. However, in Europe and in Africa Senegal, the extended treatment with synthetic anti thyroid drugs remains the first line option [1] [2]. However, this treatment is a source of relapse, a rate of 53.9\% as reported in China [5]. We deemed it appropriate to review progress made in the clinical presentation and the evolving profile of the Graves' disease in a Senegalese population under supervision at the Medical Clinic II of the Abass Ndao Hospital Centre.

\section{Patients and Methods}

This was a retrospective, descriptive study conducted at the Medical Clinic II of the Abass Ndao Hospital Center of Dakar. It focused on records of patients monitored for Graves' disease from 1 January 2010 to 31 December 2014 (5 years). All patients over 15 years old monitored for Graves' disease, on the basis of a thyrotoxicosis table associated with one or more of the following signs, were included: exophthalmos acquired, vascular diffuse goitre and pretibial myxoedema. Thyrotoxicosis was confirmed by excess thyroid hormones (free T4 and free T3) or a decrease in the ultra-sensitive Thyroid-Stimulating Hormone (TSHus). Incomplete files (lack of assessment confirmation of hyperthyroidism, incomplete clinical data) were excluded from the final analysis. A pre-arranged sheet was used as the basis for data collection. It covered the following:

-Socio-demographic data: age, sex, marital status, history and comorbidities. To study the hyperthyroidism trigger or self-maintenance factors, the patients were grouped into three categories: category 1 (marital and/or social and family conflicts such as divorce, single mothers, celibacy, difficulties within the couple and/or family or in-laws); category 2 (economic, professional, educational difficulties); category 3 (psych emotional shocks such as death of a close relative, infertility, sentimental disappointment).

-Clinical data: signs of thyrotoxicosis and signs specific to Graves' disease (goitre, exophthalmos, dermopathy). The classification of the World Health Organization, 1962, was used to classify goitre in stages. The associated pathologies were evaluated.

-Paraclinical data: values of thyroid hormones, ultra-sensitive TSH determined by immuno-radiological methods. Standards ranged from 0.17 to $4.05 \mathrm{mIU} / 1$ for TSHus, from 9 to $22 \mathrm{pmol} / 1$ for free T4 and from 2.5 to $5.8 \mathrm{pmol} / 1$ for free T3 were used. Cervical ultrasound, electrocardiogram and cardiac ultrasound were performed if required.

-Treatment data: the study of the medical treatment concerned the time limit for receiving appropriate care, prescription of drugs (synthetic anti thyroid drugs, beta-blockers and anxiolytics), dosage and treatment duration. The evaluation of surgical treatment focused on indications and the type of surgery.

-Evolution data: data on changes in patients who were monitored for at least 18 months. Complete remission was defined as a sustainable stabilization of the disease after 12 months of discontinuation of medical treatment. The complications that were investigated were cardiothyreosis, acute thyroid crisis and malignant exophthalmos.

For descriptive analysis purposes, data were presented in percentage for qualitative variables and in averages for quantitative variables. Chi-2 test were used for bivariate analysis and Fisher test for quantitative data. A p value $<0.05$ was considered statistically significant with a confidence interval of $95 \%$. Data were evaluated with Epi Info and SPSS 24.

\section{Outcomes}

\subsection{Sociodemographic Aspects}

878 cases were included. These were 709 women and 169 men, or a sex ratio (M/F) of 0.2. The average age was $34.8 \pm 12$ years (range of $16-83$ years). The most affected age group was that of $31-59$ years old with $55.1 \%$ of cases and subjects who were at least 60 years old accounted for $4.2 \%$ of cases. Married patients represented $52.8 \%$ of cases; a family thyroid dysfunction was found in $18.2 \%$ of cases. With regard to the trigger or self- 
maintenance factors, social and family and/or conjugal conflicts (category 1 ) predominated in $22.8 \%$ of cases followed by psycho emotional shocks (category 3 ) in $14.9 \%$ of cases. In $55.5 \%$ of cases, no specific psycho emotional situation had been described.

\subsection{Clinical Aspects}

The average time for consultation was $10.7 \pm 2$ months. The patients seen in the first six months accounted for $46.8 \%$ of cases. Thyrotoxicosis signs are shown in Table 1 . Signs associated with thyrotoxicosis were exophthalmos in $65.9 \%$ of cases (including $62.3 \%$ bilateral), pretibial myxoedema in $1 \%$, melanoderma $(9.1 \%$ ), alopecia (7.5\%). Goiter was found in $97.3 \%$ of which $75.3 \%$ of stages 2 and 3. Diabetes mellitus was found in $6.5 \%$ and impaired fasting glucose in $15.1 \%$ of cases. Associated pathologies were arterial hypertension (17.1\%) and obesity (3.7\%).

\subsection{Treatment and Evolutive Data}

The average starting treatment dose with synthetic anti thyroid drugs (SAT) was $37 \pm 9 \mathrm{mg} /$ day of Carbimazole. This dose was $30-40 \mathrm{mg} /$ day in $62.7 \%$ and more than $40 \mathrm{mg}$ /day only in $25.5 \%$ of cases. Beta-blockers were prescribed in $64 \%$ and anxiolytics in $40.5 \%$ of cases.

Among our patients, $336(38.2 \%)$ were lost to follow up. These were mainly women (95.4\%), subjects aged $31-59$ years $(61.3 \%)$. The number of lost to follow-up was the highest one $(11 \%)$ after the first consultation, then $10 \%$ after the first check of the $3^{\text {rd }}$ month.

Among the 542 patients who were monitored for more than 18 months, the average duration of treatment of attack was 5.6 months. This duration was 3 months in $42.2 \%$ and 6 months in $25 \%$ of cases. In 56 patients $(10.3 \%)$, the maintenance treatment could not be administered within 12 months of follow-up because of a lack of thyroid balance. Patients' attendance was only $17.7 \%$ while their compliance stood at $53.1 \%$.

The rate of free T4 achieved in the follow-up consultations was $95 \%$ while that of TSH us and blood count stood at $12 \%$ and $80 \%$, respectively. The normalization of the free T4 stood at $31.1 \%$ in the 3 rd month and $24.7 \%$ from the 6th month after the start of treatment with SAT. The average time until the occurrence of iatrogenic hypothyroidism was 15.6 months. The latter was found in $10 \%$ of patients in each quarterly check. Complete goitre regression was observed in $16.4 \%$ and that of exophthalmos in $11 \%$ of cases. Complications were found in $13.9 \%$ of cases. These were cardiothyreosis $(11.9 \%)$ and malignant exophthalmos $(1.1 \%)$.

Remission was achieved in 198 cases $(36.5 \%)$. Only stage of goiter $(\mathrm{p}=0.007)$ and initial free $\mathrm{T} 4$ value $(\mathrm{p}=$ $0.003)$ were statistically associated with remission. Table 2 shows the characteristics of patients in remission. The relapse rate stood at $28.4 \%$.

Table 1. Distribution of clinical signs.

\begin{tabular}{ccc}
\hline Clinical signs & Number of patients $(\mathbf{n}=\mathbf{8 7 8})$ & Percentage \\
\hline Palpitation & 730 & $83.1 \%$ \\
Weight loss & 702 & $79.9 \%$ \\
Trembling & 610 & $69.4 \%$ \\
Insomnia & 447 & $56.7 \%$ \\
Thermophobia & 486 & $55.3 \%$ \\
Asthenia & 471 & $53.6 \%$ \\
Excessive perspiration & 440 & $50.1 \%$ \\
Irritability and nervousness & 417 & $4.4 \%$ \\
Sign of weakening of muscles & 255 & $29 \%$ \\
Diarrhoea & 209 & $23.8 \%$ \\
Polyuria and polydipsia & 172 & $19.5 \%$ \\
Genito-sexual disorders & 121 & $1.3 \%$ \\
\hline
\end{tabular}


Table 2. Characteristics of patients in remission.

\begin{tabular}{cccc}
\hline Parameters studied & Patient in remission $(\mathbf{n}=\mathbf{1 9 8})$ & p value \\
\hline Age groups (years) & $(16-40)$ & $129(65.2 \%)$ & 0.63 \\
Sex & $\geq 40$ & $69(34.8 \%)$ & 0.90 \\
& Female & $165(83.4 \%)$ & $0.007^{*}$ \\
Stage of goiter & Male & $33(16.6 \%)$ & 0.10 \\
Exophthalmos & Stage $0-1$ & $65(32.8 \%)$ & $134(67.2 \%)$ \\
SAT starting dose (mg/l) & Stage $2-3$ & $127(64.2 \%)$ & $71(35.8 \%)$ \\
& yes & $85(42.9 \%)$ & 0.22 \\
Initial free T4 Value (pmol/l) & No & $113(57 \%)$ & $89(45 \%)$ \\
\end{tabular}

*Statistically significant link.

Seventy patients $(14.5 \%)$ had received total thyroidectomy. The average age of patients was 34 years and among them, there were 52 women and 18 men. The indication for surgery was a recurrence in $37.1 \%$, a medical treatment failure in $34.2 \%$, a cardiothyreosis in $27.1 \%$ and a malignant exophthalmos in $1.4 \%$ of cases.

\section{Discussion}

\subsection{Sociodemographic Aspects}

Graves' disease turns out to be basically a predominantly female disease. In the literature a frequency of 7 - 10 women for one man is reported [1]. The average age of our patients was 35 years with a peak between 31 and 59 years. This corroborates the results reported by Krull et al. [4] in Switzerland who reported a peak of Graves' disease incidence between 30 and 50 years. In our study, social and family and/or conjugal conflicts were found in $22.8 \%$ of patients. Family and especially conjugal stress in women married may be major aetiological factors for Graves' disease. Diop et al. [1] and Sidibé et al. [6] have shown the role of these factors in the onset and maintenance of the disease.

\subsection{Clinical Aspects}

The more or less complete thyrotoxicosis syndrome was intense with a predominance of general, cardiovascular and neuropsychic signs. The frequency of associated signs such as goitre and exophthalmos is in line with the local data sets [1]. None of our patients received the dosage of anti thyroid antibodies or TSH receptor antibodies. Yet, according to data from the literature, TSH receptor antibodies offer diagnosis sensitivity higher than $90 \%$, especially in the absence of exophthalmos [5]. The high cost is the limiting factor of their prescription in our context.

\subsection{Therapeutic Aspects}

The therapeutic strategy is different depending on the school and continents. In our series $85.5 \%$ of patients were under medical treatment. The treatment of Graves' disease in Africa and Europe is based on the medical option [1] [2] [4]. However, in the United States, 69\% of patients receive first-line treatment with radioactive iodine [4].

Our preference for SAT is linked to their availability, in the absence of treatment with radioactive iodine, and finally the lack of access to thyroidectomy [1]. However, antithyroid drugs have only a suspense effect pending 
a spontaneous remission of the disease. In literature the recommended SAT loading dose is 40 - $60 \mathrm{mg}$ [7]. In our series, it averaged $37 \mathrm{mg} /$ day. The usual treatment regimen includes an initial treatment phase from 1 to 6 months then a maintenance treatment in reduced quantities for the following 12 months [7]. In our series $67.2 \%$ of patients received attack treatment during 1 to 6 months. The average time for the administration of the maintenance treatment in our series was 5.6 months.

Only $14.5 \%$ of our patients underwent surgery. Madieng et al. [8] in a general surgery service report a $25.3 \%$ frequency of Graves' disease in a series of 402 thyroidectomise. None of our patients had received treatment with radioactive iodine because the latter was not available. In a study conducted in 2015 in Tunisia, Ben Sellem et al. [9] showed good efficacy of the administration of high doses of iodine at the very first treatment. Iratherapy has then established itself as being an alternative choice in Graves' disease, especially in developing countries. In Nigeria, Onimede et al. [10] shared their experience regarding iratherapy. Hypothyroidism is recognized as a major side effect of it [11].

\subsection{Evolutionary Aspects}

The regression of goitre was found in $16.4 \%$ cases, and that of exophthalmos in $11 \%$ of cases. The volume of goitre and presence of exophthalmos were correlated with a greater frequency of relapse in some series [5] [12]. However in the series of Cappeli et al. [13] the goiter size and FT4 level were not predictive factors of the long-term prognosis. In the series of Shingai et al. [14] in India, a higher Technetium uptake was found to be significantly associated with relapse.

The TSH us was requested in only $12 \%$. Yet its lowered rate is a predictive factor of relapse occurrence. It is the same for the increase in TSH receptor auto antibodies [5]. Unfortunately none of our patients could receive it because of the high cost of its dosage.

Approximately $35 \%$ of patients were lost to follow-up. Among the patients who reached the legal treatment duration, only $36 \%$ had a sustained remission. Our results are consistent with those reported of $32.7 \%$ in India [14], 46\% in China [6] and 41.9\% in Pakistan [15]. However, in Mexico Bolanos et al. [12] reported a lower remission rate of $17.5 \%$. Our low rate can be explained by the low level of compliance and attendance of our patients but also by the high grade of goitre and the high level of free T4 value at diagnosis.

The relapse rate was $28.4 \%$ in our series. Rates of $53.9 \%$ and $82.5 \%$ were reported by Lin et al. [5] in China and Bolanos et al. [12] in Mexico, respectively. In India 19.2\% of patients in remission in the series of Shingai et al. [14] relapsed.

Limitation of our study was:

-It's a retrospective study.

-Para clinical data like TSH receptor auto antibodies were not performed in patients because their cost is expensive.

\section{Conclusion}

Graves' disease is a common disease in Senegal as evidenced by the number of cases compiled over five years. Socio-demographically, it remains a disease affecting young women and does not show any clinical feature except the severity of thyrotoxicosis and the significant volume of goitre associated with late treatment. Therapeutically prolonged medical treatment is the preferred option, but the number of patients lost to follow-up is significant and relapses are common. It is therefore essential to expand the indications for surgery but also to promote the development of treatment with radioactive iodine.

\section{References}

[1] Diop, S.N., Diédhiou, D., Sarr, A., Ndour Mbaye, M., Sylla, O., Ba, K. and Ka-Cisse, M.S. (2011) Psychological Aspects and Psychiatric Manifestation of Grave's Disease about 104 Cases in Senegal. Rev Cames, 12, 62-64.

[2] Monabeka, H.G., Bouenizabila, E. and Ondzotto, G. (2005) Prise en charge des hyperthyroïdies au CHU de Brazzaville, Congo. Bulletin de la Société de Pathologie Exotique, 98, 91-93.

[3] Abraham, P., Avenell, A., Park, C.M., Watson, W.A. and Bevan, J.S. (2005) A Systematic Review of Drug Therapy for Graves' Hyperthyroidism. European Journal of Endocrinology, 153, 489-498. http://dx.doi.org/10.1530/eje.1.01993

[4] Rebecca, B.S., Burch, H.B. and Cooper, D.S. (2011) Hyperthyroidism and Other Causes of Thyrotoxicosis: Manage- 
ment Guideline of the American Thyroid Association of Clinical Endocrinologists. Endocrine Practice, 21, 593-646.

[5] Liu, L., Lu, H., Liu, Y., Liu, C. and Xun, C. (2016) Predicting Relapse of Graves’ Disease Following Treatment with Antithyroid Drugs. Experimental and Therapeutic Medicine, 11, 1453-1458.

[6] Sidibé, A.T., Dembélé, M. and Diarra, A.S. (2007) Hyperthyroidism in Children. Experience in Internal Medicine in Mali. Annals of Endocrinology, 68, 177-180. http://dx.doi.org/10.1016/j.ando.2007.05.003

[7] Cooper, D.S. (2005) Antithyroid Drugs. The New England Journal of Medicine, 352, 905-917. http://dx.doi.org/10.1056/NEJMra042972

[8] Dieng, M., Cissé, M., Ndour, M.D., Konaté, I., Touré, A.O., Ka, O., Dia, A. and Touré, C.T. (2010) Indications and Results of Thyroidectomy Realized in a General Surgery Department: About 402 Patients. Rev Afr Chir Spec, 4, 5-10.

[9] Ben Sellem, D., Zaabar, L., Dhaouadi, B., Letaief, B. and Ben Slimene, M.F. (2015) Maladie de Basedow: Efficacité des fortes activités d'irathérapie. Annals of Endocrinology, 76, 422. http://dx.doi.org/10.1016/j.ando.2015.07.396

[10] Onimede, Y.A., Ankrah, A. and Adedapo, K.S. (2016) Outcome of Radioiodine Therapy in a West African Population. World Journal of Nuclear Medicine, 15, 24-29.

[11] El-Sayed Husseni, M.A.E.K. (2016) The Incidence of Hypothyroidism Following the Radioactive Iodine Treatment of Grave's Disease and Predictive Factors Influencing Its Development. World Journal of Nuclear Medicine, 15, 30-37.

[12] Bolanos, F., Gonzalez-Ortiz, M., Duron, H. and Sanchez, C. (2002) Remission of Grave' Hyperthyroidism Treated with Methimazole. Revista de Investigación Clínica, 54, 307-310.

[13] Cappelli, C., Gandossi, E., Castellano, M., Pizocarro, C., Agosti, B., Delbarba, A., Pirola, I., De Martino, E. and Rosei, E.A. (2007) Prognosis Value of Thyrotropin Receptor Antibodies (TRAB) in Grave' Disease: A 120 Months Prospective Study. Endocrine Journal, 54, 713-720. http://dx.doi.org/10.1507/endocrj.K06-069

[14] Singhal, N., Praveen, V.P., Bhavani, N., Menon, A.S., Menon, U., Abraham, N., Kumar, H., Jay Kumar, R.V., Nair, V., Sundaram, S. and Sundaram, P. (2016) Technetium Uptake Predicts Remission and Relapse in Grave's Disease Patients on Antithyroid Drugs for at Least 1 Year in South Indian Subjects. Indian Journal of Endocrinology and Metabolism, 20, 157-161. http://dx.doi.org/10.4103/2230-8210.176360

[15] Ishtiag, O., Wasseem, S., Haque, M.N., Islam, N. and Jabbar, A. (2009) Remission of Graves' Disease after Oral Anti-Thyroid Drug Treatment. Journal of the College of Physicians and Surgeons-Pakistan, 19, 690-693.

\section{Submit or recommend next manuscript to SCIRP and we will provide best service for you:}

Accepting pre-submission inquiries through Email, Facebook, LinkedIn, Twitter, etc.

A wide selection of journals (inclusive of 9 subjects, more than 200 journals)

Providing 24-hour high-quality service

User-friendly online submission system

Fair and swift peer-review system

Efficient typesetting and proofreading procedure

Display of the result of downloads and visits, as well as the number of cited articles

Maximum dissemination of your research work

Submit your manuscript at: http://papersubmission.scirp.org/ 